\title{
Influence of Social Media in the Dissemination of Employment Opportunities in Sultanate of Oman
}

\author{
Meeya Nawazkhan, Al-Qalhati Fawziya, and Al Hashemi Ahlam
}

\section{ABSTRACT}

\begin{abstract}
Social media presently plays a vital role in searching for jobs and the recruitment of employees in all industries across the world. It is used both by job seekers and employers prominently in generating employment opportunities. This research work is carried out to study the influence of social media in the dissemination of employment opportunities with the objectives of (1) to study the different social media used by job seekers in searching for jobs, (2) to find the most preferred social media in searching for jobs and (3) to explore the effectiveness of social media by the job seekers in searching for jobs. The results revealed that more job seekers use online job sites to find jobs and they perceive that WhatsApp is the most preferred social media in finding jobs, followed by Google+, Instagram and Twitter. It is also found that information quality, the scope of networking and privacy $\&$ safety are the factors affecting the effectiveness of social media in finding job opportunities.
\end{abstract}

Keywords: Searching Job, Social Media, Social Media Oman, Social Media to Search Job.

\author{
Submitted : December 30, 2021 \\ Published : February 22, 2022 \\ ISSN: $2507-1076$ \\ DOI: $10.24018 /$ ejbmr.2022.7.1.1239 \\ Meeya Nawazkhan* \\ Faculty, Department of Business Studies, \\ University of Technology and Applied \\ Sciences - Ibra, Sultanate of Oman. \\ (e-mail: nawaz@ict.edu.om) \\ Al-Qalhati Fawziya \\ Graduating Student, Department of \\ Business Studies, University of \\ Technology and Applied Sciences - Ibra, \\ Sultanate of Oman. \\ Al Hashemi Ahlam \\ Graduating Student, Department of \\ Business Studies, University of \\ Technology and Applied Sciences - Ibra, \\ Sultanate of Oman. \\ *Corresponding Author
}

\section{INTRODUCTION}

Now a day the prominence of using social media becomes widespread. It is estimated that more than 3.6 billion people are using social media worldwide in 2020 and the usage is expected to reach 4.41 billion approximately in 2025 (Clement, 2020). This exponential growth is possible due to the development of infrastructural facilities, availability of cheap mobile devices, and increase in consumption. On average, the users of the internet spend 2 hours and 24 minutes a day in social media and messaging applications. As of January 2020, the usage rate of social media was $49 \%$ worldwide.

The most popular social media in terms of the number of monthly active users worldwide is Facebook (2,701 million) followed by YouTube and WhatsApp (Clement, 2020). Social media has grown rapidly in Oman. According to a report by the National Centre of Statistics and Information (Times News Service, 2019) that studied the use of social media by Omanis in March 2019, 94\% of Omanis use social networking sites. The survey also indicated that on average Omanis have up to three accounts in different sites and use social media for up to six hours a day. WhatsApp is used by 93\% of Omani social media users followed by YouTube with $71 \%$ and Instagram with $50 \%$. Omani women prefer using Snapchat, Instagram, and YouTube while Omani men prefer using Facebook, Twitter, and Imo. One-third of Omanis use social media to purchase or search for goods and services, and one-fifth of Omanis for commercial purposes.
Social media presently plays a vital role in searching for jobs and the recruitment of employees in all industries across the world. It is used both by job seekers and employers prominently in generating employment opportunities. Moreover, the usage of social media is cost-effective for both employers and job seekers to search the potential job opportunities. The purpose of social media is to share socially needed information among people. Nowadays social media became an inevitable part of social life. So social media can be positively utilized for getting employment by the job seekers and searching efficient workforce by the recruiters. The World Bank reported that the unemployment rate among Omani youth ranging from 15 to 24 years of age was $13.186 \%$ in 2019 (World Bank, Youth Unemployment Rate for Oman, 2019). Employment for economic growth is similar to what oxygen is to human existence (Patton, 2012). If social media is used for the dissemination of information on employment opportunities the rate of unemployment may fall which might lead to economic development.

The current research on the use of social media for the dissemination of employment opportunities in the context of the Sultanate of Oman is insufficient. Therefore, the researchers identified this topic to channel information on employment opportunities through social media with the objectives of (1) to study the different social media used by job seekers in searching for jobs, (2) to find the most preferred social media in searching for jobs and (3) to explore the effectiveness of social media by the job seekers in searching for jobs. 


\section{LITERATURE REVIEW}

Kajanová et al. (2017) examined the significance of social media in searching for jobs and the attitudes of young students of Generation Y towards searching for jobs through social media. Their study revealed that more than $74 \%$ of respondents used social media for searching for jobs and more than $68 \%$ of respondents got a job offer from using social media. They also highlighted that the usage of social media especially LinkedIn in searching for jobs will be increased in the days to come.

Hosain and Liu (2020) examined how the passive job seekers perceived LinkedIn as a job-searching tool. The study employed Focus Group Discussion, a qualitative research method with 150 job seekers who were regular users of LinkedIn to collect primary data using purposive convenience sampling. The study found that LinkedIn acts as one of the desired job-searching tools among the passive job seekers in terms of its information quality and cost-effectiveness. The job seekers did not bother much about the issues relating to privacy, fairness, and ethics on LinkedIn in searching for jobs.

Acikgoz and Bergman (2016) commented that the wider presence of jobseekers in social media and active use of social media helps employers to proactively explore and find jobseekers. The researchers also commented that even though Facebook is popular, professionally oriented social networking sites (e.g., LinkedIn) are probably the better tools in actively searching job seekers.

Zhitomirsky-Geffet and Bratspiess (2015) examined the effectiveness of Facebook and LinkedIn in searching for jobs. The results showed that even though LinkedIn was perceived as a more effective social network in searching jobs than Facebook, the level of actual helpfulness of both the networks in searching jobs was similar. It was also found that there is an association between usage of the networks and the perceived effectiveness of the networks in searching jobs. The study recommended that jobseeker who prefer jobs that provide more income, relating to senior positions and of the technology profession to use LinkedIn along with Facebook. The study concluded that posting of maximum possible information in both networks will increase the chance of the network's effectiveness in finding jobs.

Janta and Ladkin (2013) studied the role of social media on the job searching strategies adopted by unemployed migrants of Poland in the United Kingdom's hospitality sector. In the study, the researchers incorporated the findings of their previous studies done in 2009, 2011 and 2012. The migrants who joined the hospitality sector acted as recruitment agents of their employers - advertised the job opportunities in the Polish internet sites and shared their knowledge with respect to searching jobs with the Polish's unemployed migrants. They used mixed methods approach - firstly, exploratory fieldwork followed by six interviews with the hospitality workers. The findings of the study showed that the social media and weak ties between Polish (i.e., employed and unemployed) assisted the migrants in searching and getting jobs in the UK. It was also found that networks through weak ties provided the job seekers information on job opportunities, working environment, dishonest employers \& employment practices, need of language skills and opening

\section{bank account.}

Buettner (2016) examined the role of a number of contacts in career-oriented social networking sites on the success of job seekers in getting jobs. The effect of effort expectancy, performance expectancy, price value, habit, social influence, hedonic motivation and facilitating conditions on the intention of job seekers in using the sites to search for jobs. They found that the association between the number of contacts/connections in the sites and the effectiveness in searching jobs was significantly negative. It was also found that the behavioral intention of job seekers was influenced mainly by the factors such as facilitating conditions and habit; slightly by performance expectancy and hedonic motivation; but not at all by effort expectancy, social influence, and price value.

Plummer et al. (2011) examined the behavioral intentions of job seekers in applying for jobs using social media. The study examined the factors such as privacy concerns, provision of information, perceived trust in the selection process, performance expectancy, risk beliefs about the feature that demonstrate social networking connections between jobseekers and potential recruiters. The study found that variables such as trusting beliefs or perceptions of justice in the selection process, information privacy concerns and perceived risk such as loss of job opportunities while using social media in searching jobs were the major factors affecting the intentions of job seekers applying for jobs. It was also found that job seekers avoided keeping personal information on social media to protect their privacy and to minimize the risk of losing job opportunities.

Al-Amin et al. (2019) explored the impact of social media on job seekers' perceptions over usage of social media in searching jobs. The research used a mixed-method approach in which a questionnaire survey and interview were conducted. The job seekers perceived many advantages of using social media for searching jobs such as easy to search and apply, user-friendly, fast process, effective tool for searching jobs, direct response from employer, flexibility, cost reduction in job search and fewer formalities. Even though there were many advantages of searching for jobs over social media the study found some challenges too like including fake recruitment, security threats, unsecured or betrayed, insecurity, deception and hiring for a short time. The researchers opined that recruitment over social media will be effective and efficient if all the above unethical practices are eradicated.

Social media can also be used to gather information on employment opportunities. According to the survey done by Brotherton (2012), 64\% of employers have successfully recruited employees using social networks. Mehmood and Taswir (2013) identified that $80 \%$ of Omani students have started using social networking sites for academic purposes as well as exploring career opportunities. According to Nikolaou (2014), HR professionals use social networking sites widely to recruit employees. At this juncture, one should not neglect the flip side of using social media to search for jobs. Brown and Vaughn (2011) opined that the information posted on social media such as pictures, thoughts, videos, biographical information and other personal information shared by applicants may affect the likelihood of considering them for further review by the employers. 


\section{RESEARCH METHODOLOGY}

This research study is focused on the North and South Sharqiyah regions of Sultanate of Oman. The population of the study includes the students and graduates of educational institutions from these regions. The convenience sampling method is used to collect primary data from 70 participants. This study mainly uses primary data which was collected online through a well-constructed questionnaire. The perception of the jobseekers was obtained using a 5-point Likert scale. The study variables are quality of the information in social media, the popularity of social media among job seekers, the scope of networking in social media, easiness of navigation of social media, privacy and safety in social media and effectiveness of social media in searching jobs (Masa'd, 2015). The items of the variables have been identified through previous studies such as Shamala, et al. (2017), Cauter, et al. (2017), Wang (2018), Acikgoz and Bergman (2016), Janta and Ladkin (2013), Buettner (2016), Ellahi and Bokari (2013), Plummer, et al. (2011), Abril, et al. (2012), Black et al. (2015), Zhitomirsky-Geffet and Bratspiess (2015), Kajanováet et al. (2017) and Al-Amin et al. (2019). Statistical Package for Social Sciences (SPSS) is used to analyze the data. Statistical tools such as mean, weighted average and multiple regression analysis were employed for meaningful analysis.

\section{A. Study Variables}

This study uses five independent factors such as quality of information, popularity, the scope of networking, easiness of navigation and privacy and safety of social media and a dependent factor, effectiveness of social media in searching jobs.

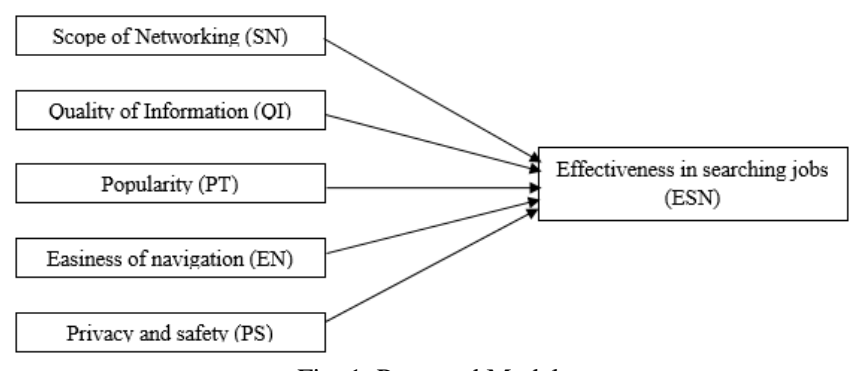

Fig. 1. Proposed Model.

Information quality refers to the quality of information available in social media that fulfills the information needs of jobseekers. Normally job seekers depend on the job information available on social media while applying for jobs. The eight perceived determinants of information quality - reliability, accuracy, up-to-date, timely, relevance, usefulness, sufficiency and completeness are included in our questionnaire (Shamala, et al., 2017, Cauter, et al. 2017 and Wang, 2018). Popularity refers to the level of attraction of social media among job seekers whereas scope of networking is the coverage of networks/connections and the number of users involved in the social media. Easiness of navigation covers the functions of social media that help the users in finding needed information from various pages easily, quickly, and effectively without difficulty through a nice search engine (Ellahi and Bokari, 2013). Privacy denotes the degree of protection and safety that the user perceives against intrusion by third parties. The effectiveness of social media implies the degree to which job searching will be successful using social media.

\section{RESUlt AND DisCUSSION}

\section{A. Demographic Profile}

Demographic information supplies data about the characteristics of research participants and is important for the researchers as well as readers to understand certain background features of the participants such as gender, age, educational qualification, etc.

\begin{tabular}{lcc} 
TABLE I: DEMOGRAPHIC DETAILS OF SAMPLE RESPONDENTS \\
\hline & Frequency & Percent \\
\hline Gender & 29 & 41.4 \\
$\quad$ Male & 41 & 58.6 \\
$\quad$ Female & 51 & 72.9 \\
Age & 19 & 27.1 \\
$\quad$ Less than 25 & & \\
26-30 years & 35 & 50 \\
Educational Qualification & 26 & 37.1 \\
$\quad$ Diploma & 9 & 12.9 \\
$\quad$ Post Graduate & & \\
$\quad$ Others & 12 & 17.1 \\
Social media usage in Hours & 12 & 17.1 \\
$\quad$ Less than 1 hour & 16 & 22.9 \\
1-2 hours & 15 & 21.4 \\
2-3 hours & 15 & 21.4 \\
3-4 hours & & \\
More than 4 hours &
\end{tabular}

From the above table, it is evident that female participants are more than male participants and most of the participants fall under the age group of less than 25. The participation of diploma students is the highest out of all the respondents and most of the partipants used social media on an average 2 to 3 hours a day.

\section{B. Popular Social Media in Searching Jobs}

The data collected is analyzed using the weighted average method. The chart below shows the ranking of social media based on the weights given.

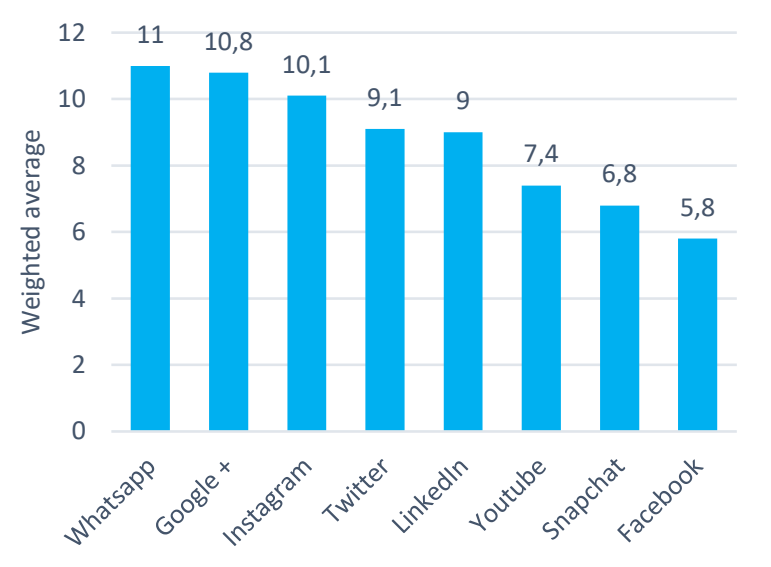

Fig. 2. Jobseekers ranking of social media for searching jobs.

The above chart shows the ranking of social media that can be used for searching jobs regularly by the participants. WhatsApp is perceived as the most popular social media for job searching by the participants followed by Google+, Instagram, Twitter, LinkedIn, YouTube, Snapchat, and Facebook. 


\section{Effectiveness of Social Media in Searching Jobs}

The main purpose of this study is to analyze the effectiveness of social media. The study uses five independent variables to estimate their effect on the dependent variable. In this context, path analysis could be used to determine the factors that most affect the dependent variable.

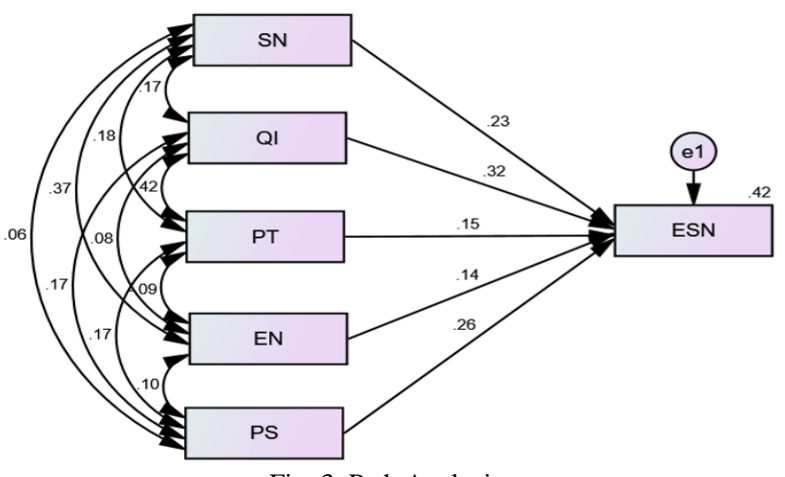

Fig. 3. Path Analysis.

TABLE II: REGRESSION WEIGHTS

\begin{tabular}{|c|c|c|c|c|c|c|c|}
\hline & & & Est. & S.E. & C.R. & $\mathrm{P}$ & $\mathrm{H}_{1}$ \\
\hline $\begin{array}{c}\text { Effectiveness } \\
\text { of S. Media }\end{array}$ & $<--$ & $\begin{array}{c}\text { Scope of } \\
\text { networking }\end{array}$ & 0.128 & 0.058 & 2.211 & 0.027 & Accepted \\
\hline $\begin{array}{c}\text { Effectiveness } \\
\text { of S. Media }\end{array}$ & $<--$ & $\begin{array}{l}\text { Quality of } \\
\text { Information }\end{array}$ & 0.241 & 0.078 & 3.072 & 0.002 & Accepted \\
\hline $\begin{array}{c}\text { Effectiveness } \\
\text { of S. Media }\end{array}$ & $<--$ & Popularity & 0.093 & 0.065 & 1.422 & 0.155 & Rejected \\
\hline $\begin{array}{c}\text { Effectiveness } \\
\text { of S. Media }\end{array}$ & $<--$ & $\begin{array}{l}\text { Easiness of } \\
\text { Navigation }\end{array}$ & 0.085 & 0.061 & 1.397 & 0.163 & Rejected \\
\hline $\begin{array}{c}\text { Effectiveness } \\
\text { of S. Media }\end{array}$ & $<-$ & $\begin{array}{c}\text { Privacy and } \\
\text { Safety }\end{array}$ & 0.143 & 0.053 & 2.706 & 0.007 & Accepted \\
\hline
\end{tabular}

TABLE III: STANDARDIZED REGRESSION WEIGHTS

\begin{tabular}{lccc}
\hline \multicolumn{2}{c}{ Path } & & Estimate \\
\hline Effectiveness of Social Media & $<---$ & Scope of networking & 0.225 \\
Effectiveness of Social Media & $<---$ & $\begin{array}{c}\text { Quality of } \\
\text { Information } \\
\text { Effectiveness of Social Media }\end{array}$ & 0.316 \\
Effectiveness of Social Media & $<---$ & $\begin{array}{c}\text { Popularity } \\
\text { Nasiness of }\end{array}$ & 0.149 \\
Effectiveness of Social Media & $<---$ & Privacy and Safety & 0.142 \\
\hline
\end{tabular}

\begin{tabular}{cc} 
TABLE IV: SQUARED MULTIPLE CORRELATIONS $\left(\mathrm{R}^{2}\right)$ \\
\hline Effectiveness of Social Media & Estimate \\
\hline
\end{tabular}

Multiple regression is a statistical technique that uses the values of several known independent variables to predict the value of an unknown dependent variable. The above results show that all the five independent variables - scope of networking (SN), quality of information (QI), popularity (PT), easiness of navigation (EN) and privacy and safety (PS) were taken as inputs simultaneously for predicting the value of a dependent variable - effectiveness of social media in searching jobs.

The $\mathrm{R}^{2}$ value (0.417) implies the moderate influence of the independent variables on the dependent variable. The value shows that the independent variables influenced the dependent variable by $41.7 \%$. So, we can conclude that the model used in the research is appropriate for studying the impact of independent variables on the dependent variable.

The regression coefficients table explains the quantity of changes impacted on the effectiveness of the dependent variable. The estimated value and $p$-value imply that scope of networking (Est. $0.225, p<0.05$ ), quality of information (Est. $0.316, p<0.05$ ) and privacy and safety (Est. $0.256, p<0.05$ ) have significant influence on the effectiveness of social media. These values also imply that popularity (Est. 0.149, $p$ $>0.05$ ) and easiness of navigation (Est. $0.142, p>0.05$ ) have no impact on the effectiveness of social media. It is also inferred that quality of information has the highest impact on the effectiveness of social media followed by privacy and safety and scope of networking. The quality of the information emerged as the strongest predictor of the effectiveness of social media in searching jobs (Teoh et al., 2013, Moghaddam et al., 2015, Wang, 2018 and Hosain and Liu, 2020) followed by privacy \& safety (Plummer et al., 2011, Ellahi and Bokari, 2013, Abril et al., 2012 and Black et al., 2015) and scope of networking (Janta and Ladkin, 2013). The popularity of social media and easiness of navigation features (Moghaddam et al., 2015 and Ellahi and Bokari, 2013) in social media don't have any impact on the effectiveness of social media in searching jobs.

\section{CONCLUSIONS}

The World Bank reported that the unemployment rate among Omani youth ranging from 15 to 24 years of age was $13.186 \%$ in 2019 (World Bank, Youth Unemployment Rate for Oman, 2019). The objectives of the research are studying different social media used by the job seekers, finding the most preferred social media of them, and examining the factors affecting the effectiveness of social media in the process of searching for jobs. To achieve these objectives, this research was conducted with the job seekers from the North and South Sharqiya regions of the Sultanate of Oman. The results reveal that more job seekers use online job sites to find jobs and they perceive that WhatsApp is the most preferred social media in finding jobs, followed by Google+, Instagram and Twitter. It is also found that information quality, the scope of networking and privacy \& safety are the factors affecting the effectiveness of social media in finding job opportunities. If social media is used for the dissemination of information on employment opportunities effectively may result in the reduction of unemployment to a certain extent which may lead to economic development.

\section{LIMITATION OF THE STUDY}

The study covers the samples from North and South Sharqiya governorates of the Sultanate of Oman. The study does not cover the students and graduates using social media from the other governorates of the country. Social media that are popular in the country (such as Twitter, Instagram, Facebook, YouTube, WhatsApp and Snapchat) were used in this research work and hence it did not cover the other social media. The results are based on a sample survey. Therefore, the result may not be applicable if the nature of the sample is different in another context. The study used five independent variables only to measure the effectiveness of social media in searching for jobs. 


\section{SCOPE FOR FURTHER RESEARCH}

The current research is done from the perspective of job seekers in using social media in the process of searching for jobs. Future research can cover the impact of social media used by the employers in the recruitment process in the context of the Sultanate of Oman so that the hidden knowledge on their perceptions and practices followed in recruiting candidates can be explored. This would assist the job seekers in knowing the expectations of employers better.

\section{REFERENCES}

Abril, P. S., Levin, A., and Riego, A. D. (2012). Blurred boundaries: Social media privacy and the Twenty-first-century employee. American Business Law Journal, 49(1), 63-124.

Acikgoz, Y. and Bergman, S. M. (2016). Social media and Employee Recruitment: Chasing the Run Away Bandwagon. Springer International Publishing, Switzerland. ISBN 978-3-319-29987-7 Pages 175-195.

Al-Amin, M., Nafi, S. M. and Amin, M. A. (2019). Use of social media for job search and application: a perspective from the job seekers in Bangladesh. Discovery Journal, 55(281), ISSN 2278-5469, EISSN 2278-5450.

Black, S. L., Stone, D. L., and Johnson, A. F. (2015). Use of social networking websites on applicants' privacy. Employee Responsibilities and Rights Journal, 27: 115-159.

Brotherton, P. (2012). Social Media and Referrals Are Best Sources for Talent. Training and Development Magazine, January 2012, 66(1), p. 24. Accessed from https://www.td.org/magazines/td-magazine/socialmedia-and-referrals-are-best-sources-for-talent.

Brown, V. R. \& Vaughn, E. D. (2011). The writing on the (Facebook) wall: The use of social networking sites in hiring decisions, Journal of Business and Psychology, 26, 219-225.

Buettner, R. (2016). Getting a Job via Career-Oriented Social Networking Sites: The Weakness of Ties. 2016 49th Hawaii International Conference on System Sciences (HICSS), Koloa, HI, 2016, pp. 21562165, doi: 10.1109/HICSS.2016.272.

Cauter, L. V., Verlet, D., Snoeck, M., and Crompvoets, J. (2017). The explanatory power of the Delone \& McLean Model in the public sector: A mixed method test. Information Polity, 22(1), 41-55.

Clement, J. (2020, November 24). Most popular social networks worldwide as of October 2020, ranked by number of active users. Statista.com. Retrieved November 25, 2020, from https://statista.com/statistics/272014/global-social-networks-rankedby-number-of-users/.

Clement, J. (2020, November 24). Number of social network users worldwide from 2017 to 2025. Statista.com. Retrieved November 25, 2020, from https://statista.com/statistics/278414/number-ofworldwide-social-network-users/.

Ellahi, A. and Bokhari, R. H. (2013). Key quality factors affecting users' perception of social networking sites. Journal of Retailing and Consumer Services, Elsevier, 20(1), 120-129.

Hosain, M. S. and Liu, P. (2020). LinkedIn for Searching Better Job Opportunity: Passive Jobseekers' Perceived Experience, The Qualitative Report, 25(10), 3719-3732, Article 13.

Janta, H., \& Ladkin, A. (2013). In search of employment: Online technologies and Polish migrants. New Technology, Work and Employment, 28(3), 241-253.

Kajanová, H., Sedláček, M., Soósová, V. (2017), Attitudes of Young People to Job Searching through Social Media: Case of Slovakia, Economics and Sociology, 10(1), 152-168. DOI: 10.14254/2071-789X.2017/101/11. ISSN 2071-789X

Masa'd, F. M. (2015). Deployment of social media in the recruitment process. Journal of Knowledge Management, Economics and Information Technology, 5(1), 1-24.

Mehmood and Taswir. (2013). The Effects of Social Networking Sites on the Academic Performance of Students in College of Applied Sciences, Nizwa, Oman. International Journal of Arts and Commerce, 2(1). ISSN 1929-7106.

Moghaddam, H. A., Rezaei, S. and Amin, M. (2015). Examining job seeker's perception and behavioral intention toward online recruitment: A PLS Path modeling approach. Journal for Global Business Advancement, $8(3), 305-325$.

Nikolaou, L. (2014). Social Networking Web Sites in Job Search and Employee Recruitment. International Journal of Selection and
Assessment, 22(2), 179-189.

Patton, M. (2012, August 27). The Key to Economic Growth: Reduce The Unemployment Rate! Forbes.com. Retrieved July 23, 2019, from https://www.forbes.com/sites/mikepatton/2012/08/27/the-key-toeconomic-growth-reduce-the-unemployment-rate/\#4c31ecb954ce.

Plummer, M., Hiltz, S. R. and Plotnick, L. (2011). Predicting intentions to apply for jobs using social networking sites: An exploratory study. HICSS 11, Proceedings of the 2011 44th Hawaii international conference on system sciences, Hawaii, United States of America, pp. $1-10$.

Shamala, P., Ahmad, R., Zolait, A., and Sedek, M. (2017). Integrating information quality dimensions into information security risk management (ISRM). Journal of Information Security and Applications, 36, 1-10.

Teoh, W.M.Y., Tan, S. C. and Chong, S. C. (2013). Factors influencing perceptions of university students towards internet recruitment. Asian Academy of Management Journal, 18(1), 123-142.

Wang, J. (2018). The effects of dimensions of social media quality on user satisfaction: a cross-cultural comparison of Thai and Chinese users. Global Journal of Arts, Humanities and Social Sciences, 6(7), 14-44. Published by European Centre for Research Training and Development UK (www.eajournals.org) ISSN: 2052-6350 (Print) ISSN: 2052-6369 (Online).

World Bank, Youth Unemployment Rate for Oman [SLUEM1524ZSOMN], retrieved July 22, 2019, from FRED, Federal Reserve Bank of St. Louis; https://fred.stlouisfed.org/series/SLUEM1524ZSOMN.

Zhitomirsky-Geffet, M. and Bratspiess, Y. (2015). Libri. 65(2), 105-118, eISSN 1865-8423, ISSN 0024-2667, DOI: https://doi.org/10.1515/libri-2014-0115.

Times News Service. (2019, June 22). Omanis spend up to six hours daily on social media. Timesofoman.com. Retrieved July 23, 2019, from https://timesofoman.com/article/1494308/oman/health/omanis-spendup-to-six-hours-daily-on-social-media. 